\title{
INTELLECTUAL AND HISTORICAL REFERENCES AND THEIR REFLECTIONS ON CONTEMPORARY APPLIED ARTS CARPETS AS A MODEL
}

Moataz Enad GHAZWAN *

${ }^{1}$ College of Fine Arts, University of Baghdad, Iraq.

\begin{abstract}
Carpet is an applied category that is distinguished by many civilized peoples in the world, especially those peoples that enjoy a great cultural heritage rich in historical vocabulary and civilized symbols that suggest human connotations that emphasized the power of thought and thinking of civilized people and in turn sought to devise those symbols in contemporary applied arts Today, in its various forms and functions. The uses of these symbols have had a very important impact in emphasizing the value of the historical and cultural symbol in contemporary carpet design. Through the foregoing, the research problem can be identified by asking the following question: What are the intellectual and historical implications by deducing the historical symbol in contemporary carpet design?

Keywords

Intellectual, Historical References, Contemporary, Applied Arts, Carpets.
\end{abstract}

\section{Introduction}

The historical symbol in contemporary applied arts: the historical symbol is an important sign that enjoys its discretion, knowledge and human connotations that give its prominent impact on various aspects of the peoples' social, cultural and even political life, and peoples without a cultural heritage lack the presence of those symbols, which differ on the contrary in the rich and multiplicity of Its lofty and human implications within the civilized peoples such as the Mesopotamian Valley, the Nile Valley, China, India, the Greeks, and others It is the process of affirming the identity and the national peculiarity of the humanism of civilization and what it left of the symbols it has left is a bright spot in the lives of its peoples. It has been questioned and devised in many modern and contemporary world cultures, especially in the field of applied arts and design. Therefore, the humanity of a civilization is a reflection of the social, its people, and its social A people or civilization is a reflection of their people's understanding of their civilization and the civilization of other peoples, and their willingness to document the interaction between them and other civilizations. Every act is intended to prevent this interaction, which is a criminal act against humanity and the right of the alleged civilization to defend humanity. The humanism of civilization does not exist without highlighting its true symbols as a facade that highlights the spirit of the peoples' civilization and its history full of human achievements and innovations that have enriched the world and established civil

* Corresponding author: web.admin@ cofarts.uobaghdad.edu.iq 
thought based on respect for the deduction of the civilized and historical symbol in various global applied arts. (Fouad Zakaria) points out that there is a difficulty in understanding the relationship between civilization (civilization) and (civilization), the opinions of thinkers on this topic have varied sharply, so some of them argued that civilization is distinguished from civilization that distinguishes the simple from the complex, and others went to the point that civilization is distinguished from civilization. Civilization is the simplest, as civilization is related to the material phenomena in the life of society in particular, while civilization is the cultural and moral phenomena in this life. Civilization has established a civilization whose human data starts from the presence of civilizational symbols that are dated by history and reveals its importance and position in the heritage and global human civilization. Especially in the field of applied arts, including the art of carpet design. Through the foregoing, each of the peoples of the earth has its own peculiarity and national identity that distinguishes it from the other, and civilization is the great and qualitative source in terms of behavior, life and perception.

In addition to design, civilization, with its human symbols, has a great role in developing human perceptions, especially the designer, who is a member of a civilized community who is affected by what his community is affected by and what surrounds it in terms of information, symbols, units, shapes and colors. There is a dialectical relationship between the concept of civilization and the concept of heritage. Civilization, in its objective concept, indicates a set of literary, artistic and scientific advances as well as the technical aspect, which is transmitted from generation to generation in one or several similar societies, and each civilization has its classes, languages and geographical boundaries. And its archaeological layers accumulated on top of each other over time. As for the (folklore) heritage, it is considered in its own sense the knowledge specialized in folklore in terms of its forms, contents and functions. Heritage is also an attempt to reveal the development of cultures, literature and arts, in various settings and stages, and there is a difference in naming heritage as an accurate term, some of them call it folklore, or folklore or Popular Myths. Heritage is also the culture or cultural elements that are received by one generation after another, or that have been passed on from one generation to another. The link between the scientific concepts of the terms civilization and heritage is a link that is directly proportional to time and its transformations, for each civilization has its own culture and its artistic, scientific and literary characteristics through a clear contact between the individual and civilization to establish the folklore distinguished by the elements of that civilization and its humanistic culture, which we can make sure that the great presence of the components of civilization In applied and industrial arts, publications, architectural designs, 
etc., it indicates the strength of its movement within the artistic work as a general concept and the strength of the presence of space-time as a special concept. The ancient Iraqi civilization or the civilization of Mesopotamia is characterized by the multiplicity of its great historical achievements, starting from writing and recording to the invention of the wheel and the creation of arts such as architecture, sculpture, pottery and others. In our research, we deal with studying the symbols of the Mesopotamian civilization in particular and devising them in the design of carpets, as the Ragdian civilization is one of the important ancient world civilizations, as the Sumerians had spread their influence over most of the lands of Mesopotamia, especially in the era of the Sumerian king (Lukal Zakizi), who After a reign that lasted for more than a quarter of a century, he became one of the most powerful kings of his time. Sargon of Akkadian was able to contest him for power and eventually triumph over him to establish his new state, the Akkadian state (2334-2154 BC) or (21-20 BC). This country for nearly twenty-five years. And then the coming of the reign of the third dynasty of Ur, or what may be called the era of the Sumerian-Akkadian revival, which was founded by the renewed king (Urmu), (2112-2004 BC) and whose rule lasted nearly one century. And then the ancient Babylonian era (2009-1094 $\mathrm{BC}$ ), and then the Kishite invasion of Babylon. To begin the era of the Assyrian state, which extended over three eras: the ancient Assyrian, the medieval, and the modern. Where Iraq witnessed the dark period with the fall of Babylon at the hands of Cyrus the Achaemenid in the year $2 \mathrm{BC}$, which ended with the conquest of Alexander in the year $21 \mathrm{BC}$. The ancient Iraqis accomplished many artistic innovations, especially in architecture and plastic arts, such as sculpture and pottery, as well as cylinder seals, which are the oldest emergence of the idea of printing in the history of human thought, as it became possible to complete many prints of scenes by simply pressing the body of the seal on the clay and rotating it. Scenes in graphic art, meaning the art of printing. The scenes of seals were distinguished by the presence of symbols representing the deities, especially the sun god (Shamash), scenes of worship and offering offerings to the goddess, drinking boards, myths, hunting scenes, animal fights, scenes of cultivation and agriculture, and other topics that distinguished In addition to the social and religious life, the cylindrical seals were distinguished by their simple symbols, with the presence of many symbols of Iraqi nature, such as fish, wild animals, and compound animals that may represent symbols of the sacred gods, as well as the scorpion and eagle as the head of the lion, and the lions and oxen that symbolize (Damzi) or the so-called deity ( Tammuz), and reed houses as a symbol of the goddess Enana (or what is called by the goddess Ishtar, the gods of fertility and growth in ancient Iraqi thought. As for flowers and their shapes, they took on a role. Great in decorating many buildings, clothes, etc., including the eight-leaf flower that the 
ancient Iraqis embodied in many of their folk art, as they were placed on jugs as a decoration and on the facades of buildings as bricks, and it is a flower of a nail-like shape that is inserted through it in the building in order to decorate it and this What was found in the decoration of the temple building of $\mathrm{Al}$ Ain in the late third millennium BC. It differs from the flower (Albion) or what is called locally in Iraq (the chamomile flower) and it is one of the most popular flowers as a symbol of fertility and tenderness in the ancient Iraqi applied arts, and it is a well-known flower of great usefulness, and it is called the flower (chrysanthemum) and is called (nettle) by the Arabs It is known in Yemen as (Mu'nis). Baghdadi houses from the beginning of the last century to now are still using the symbol of a flower of pepon or chrysanthemum in decorating the architecture of residential houses because of its association with fertility and growth and the removal of evil and envy. As well as symbols of the legendary hero (Gilgamesh), the hero of the well-known Iraqi epic (The Epic of Gilgamesh), which he expressed in the form of a horned man embracing two cows, and these drawings appeared among some of the Sumerian harps supports in the third dynasty of Ur.

\section{The bazrik carpet:}

The design of the bazric rug is therefore the oldest hand woven carpet known to mankind. The bazirk carpet is a beautiful carpet, preserved by the snow and probably woven by the Sythes, a people close to the European Indians, who lived in the northern slopes of the mountains of Iran and upper Afghanistan, and the rest of them still reside in the west and north of Iran in the city of (Saquez). The researchers used the symbols used in carpets and classified them into labels that helped differentiate between the symbols of a civilized place from the other, the most important of which are the following:

1- Trantula: It denotes an ambiguous or unknown meaning and is often found in carpets such as Kaka, Wukabistan and Sharafan.

2- The lamp: It is placed hanging in the prayer direction in Turkish carpets.

3- Angled hook: It is almost the registered trademark of all Caucasian carpets and is found in all Western Asian inscriptions in general.

4- The winged ball: It is an Egyptian inscription consisting of a small ball on both sides of it two wings that are projected. It symbolizes the power of the Egyptian rulers, and in another narration, the abundance of good deeds

5- Lucky knot: It is one of the Chinese inscriptions and is found in abundance in Samarkand carpets and Chinese products as it is used in the Caucasus.

6- The star: appears frequently in Caucasian carpets, while the vertical star appears frequently in Turkish carpets. 
7- The Tree of Life: It is found in abundance in most Persian carpets. In India, it is considered a symbol of merit for those who do a great job.

8- Wild Dragon; It appears with five claws and wings and has scales over its skin, and in India it is symbolized by death. In Japan, it has only three legs, and we find it in Chinese carpets.

9- Russian eagle: A large two-headed eagle with a crown.

10- Chinese clouds: It is one of the famous Mongolian inscriptions and is sometimes found in Caucasian and Kurdish textiles, and they symbolize the tower (Irasa Major), which the people of Mongolia believed that God had settled in it.

11- The comb: It is a symbol used by Muslims that indicates cleanliness and is used on prayer carpets, especially in Dagestan carpets.

12- The bat and the palm tree: the Chinese used it in the design of carpets because it is a symbol of good luck, activity and love of work.

13- The scarab, or what is called the scarab: where the Chinese take it as a symbol of resurrection and life, but in India it symbolizes property, and likewise in Egypt it used wings in the form of fans made of peacock feathers. "Scarab in ancient Egyptian thought is a picture of self-creation Since the Egyptians believed that it came into existence by itself from a dung ball whose purpose was in fact to protect the eggs and the larva, in early times it was actually equated with the Creator Atum, and was considered a form of the sun god.

14- The circle: It is used in most Chinese inscriptions, as it symbolizes eternity, but in India, it indicates a sinister fortune and has a great impact on their inherited beliefs. "This symbol has also spread outside Chinese culture to express the interaction between opposites, or what we can call opposites. Contrast. (Wossius Wong) defines this symbol as follows: Yin (Yin) and Yang (Yang) form (Tai-shi) and be as a bright form that extends from the top and contracts to the bottom and the other on the contrary, (and the yin and yang) are intertwined, there can be no one. Without the other, (yin and yong) symbolize femininity and masculinity, but their meaning goes beyond this contradiction to other oppositions such as negativity and positivity, submissiveness and aggression, weakness and strength, softness and rigidity, retreat and progress, concavity and simplicity, introversion and release, stillness and movement, giving and taking, and denoting Man and woman, the earth and the sky, the dark side and the bright side of the mountain, so the interaction between the statement and the yang) generates all things.

15- Persian victory: It contains a lion carrying a sword in its right paw and a shining sun 
behind it, because they used to worship the sun, and the lion had hosted their victories by the war raids, and the sword was used as a symbol of strength and oppression and used a lot in their inscriptions.

\section{Recommendations:}

- Continuing to draw inspiration from the ancient and Islamic cultural heritage in the applied arts, especially the contemporary textile industries, as heritage is considered in terms of its artistic components

- Aesthetics is important in the popularity and success of design by emphasizing the important pivotal role of sustainable development strategies.

- Achieving civilizational communication or integration by linking the past with the present in the designs of all textile industries, using the inspired symbols and transforming them to serve the design and highlighting its role and importance in the service of society and the development of public taste.

- Using modern production methods in Iraqi textile designs by using the computer and its new systems and keeping pace with the development taking place in it in line with the design programs and topics.

- The designs prepared for the weaving of its various types and production techniques, which are deduced from the civilizational symbols and their historical origins, must be identical to the historical content.

- The use of the local character in the colors of the carpets in particular, with the diversity in the use of these colors, noting that it is necessary that the colors proposed in the prepared design are commensurate with the ancient civilization and the local environment, and the need to familiarize themselves with the international designs, production methods and advanced technologies in the textile industrial product.

- Adopting designs that depart from the norm, inspiring the civilized self not on the basis of transforming it into a decorative vocabulary, but rather designs that do not necessarily adhere to the processes of repetition, symmetry, etc., that is, the diversity in the merging of several different units in the form of a narrative or continuation of the story of civilization.

- Preparing designers specializing in textile design and manufacture, by training and directing them in studying design through its foundations and technical elements, as well as training in modern artistic production techniques using computers, its modern systems and programs, and in accordance with the sustainable development strategy.

- The media influence and its observance in presenting ideas and the connotations of 
symbols and their merging with each other, so that it becomes a media language that directs a civilized idea and a connotation that may be local (Iraqi, Egyptian, Syrian, etc.) Arabic, Islamic, Eastern..etc to the world.

- Paying attention to the production aspect of the textile industrial product in terms of design and implementation, taking into account the issue of commercial promotion to the world and making it with a strong competitive value in light of global economic and trade development.

- Employing the traditional decorative elements in a contemporary way and opening the horizons of textile designers in laboratories to devise from the arts of human civilization in contemporary and advanced formulas that embrace the spirit of the times.

- To spread this design trend to all sectors of the Arab textile industry, especially carpets, in order to advance the reality of the textile industry at the level of the Arab world.

\section{References:}

1- Abu Hantash, Ibrahim: Principles of Design, Dar Al-Baraka Publishing House, Amman 3rd Edition, 2000 AD.

2- Ahmed Fouad Nour El-Din and Mostafa Mohamed Hossein: The Art of Handmade Carpets, Dar Al Ma'arif, Egypt, Cairo, 1963.

3- Al Yassin, Muhammad Hasan: The Lexicon of Botanicals and Agriculture, Al-Araqi Scientific Complex, Baghdad, 1986

4- Otis, David and John: The Emergence of Civilization, translated by Lotfi El-Khoury, House of Cultural Affairs, Baghdad, 1988.

5- Iyad Hussein Abdullah: The Art of Design, Philosophy, Theory, and Implementation, Part 1, Department of Culture and Information, Sharjah, 2008 AD.

6- Barrow, Andrei: Sumer Arts and Civilization, translated by Dr. Issa Salman and Salim Taha Al-Tikriti, Ministry of Culture and Information, Baghdad, 1979.

7- Barrow, Andreya: Assyria, translated by Dr. Issa Salman and Salim Taha Al-Tikriti, AlRasheed Publishing House, Baghdad: 1980.

8- Jabbour Abdel-Nour: Literary Dictionary, Dar Al-Alam for Millions, Beirut, 1979.

9- Jamil Saliba: The Philosophical Dictionary, Ja`zin, The Lebanese Book House, Beirut, 1983. 10- Jawad Ali: Idols of Writings, Dar Al-Warraq, London: 2007.

11- George Hanna: The Historical Truth, House of Science for the Millions, Beirut, 1958 AD. 12- Al-Husayni, Nabeel: The sources of vision in art, the Arab Center for Culture and Science, Beirut: 1982. 
13- Erje Abd Allah: The Dramatic Elements in the Epic of Gilgamesh and in the Sumerian and Babylonian Myths, his unpublished doctoral thesis, 2001 AD.

14- Reid, Herbert: Art and Industry: Foundations of Industrial Design, translated by Dr. Fatah al-Bab Abdel Halim and Mahmoud Mahmoud Youssef, The World of Books, Cairo: B.T.

15- Zakaria, Fouad: Man and Civilization, Misr House for Printing, Cairo: 1991 AD.

16- Zahir Sahib: The Legend of the Near Time, a study of the new Akkadian and Sumerian arts, Dar Al-Asdekaa for Printing and Publishing, Baghdad: 2010.

17- Sacks, Harry: Everyday Life in the Ancient Iraq (Babylon and Assyria), translated by Kazem Saad Al-Din, House of General Cultural Affairs, Baghdad: 2000 AD.

18- Saeed Alloush: Dictionary of Contemporary Literary Terms, Lebanese Book House, Beirut, 1985.

19- Al-Shall, Abdul-Ghani Al-Nabawi: Terms in Art and Art Education, King Saud University, Riyadh, 1984 AD.

20- Al-Sharif, Salah al-Din: Oriental Carpets, Ministry of Culture, Damascus: 1996.

21- Al-Shams, Majid Abd-Allah: God, Man, and the Mysteries of the Gardens of Babylon, Ala Al-Din House, Damascus: 2007.

22- Sobhi Anwar Rashid and Hayat Abd Ali Al-Houri: Confirmed Seals in the Al-Araqi Museum, Ministry of Culture and Information, Baghdad: 1982.

23- Al-Tayyesh, Ali Ahmed: The Early Islamic Decorative Arts in the Umayyad and Abbasid Era, Zahra Al-Sharq Library, Cairo, 2000 AD.

24- Taha Baqer: The Epic of Gilgamesh and Other Stories about Gilgamesh and the Flood, Ministry of Culture and Information, Baghdad: 1980 AD.

25- Taha Baqer: An Introduction to the History of Ancient Civilizations, Dar Al-Warraq, London: 2009.

26- Abdel Hamid Younes: Lexicon of Folklore, Lebanon Library, Irut 1983.

27- The Stubbornness of Ghazwan: Time in the Epic of Gilgamesh, Echoes of Literary Critical Studies, Arab Writers Union, Damascus: 2000 AD.

28- Al-Anteel, Fawzi: Folklore: What is it ?, Madbouly Library, Cairo: 1987 AD.

29- Ayyad Abu Bakr Hashem and Aqeel Mahdi Yusef: History and Taste of Arts, Department of Educational Means and Supplies, Tarabulus / Libya, 2003 AD.

30- Fayed, Arul and Ayen Kasak: Al-Kawakeb in the Ancient Iraq, translated by Alaa Khayro, Dar Al-Ma'moun, Baghdad: 2013.

31- Kamal Eid: Philosophy of Literature and Art, Arab Book House, Libya - Tunisia, 1978.

32- Lorker, Manfred: A Dictionary of Deities and Symbols in Ancient Egypt, translated by 
Salah al-Din Ramadan, Madbouly Library, Cairo, 2000 AD.

33- Muhammad Rashid Nasser Zouk: The Language of Adam, Gross Press, Tarabulus / Lebanon, 1995 AD.

34- The Philosophical Dictionary: The Arabic Language Academy, the Arab Republic of Egypt, the General Authority for the Affairs of the Emiri Press, Cairo, 1983.

35- The Epic of Gilgamesh: translated from Al-Akkadiyya, by Dr. Sami Saeed Al-Ahmad, Dar Al-Jalil, Dar Al-Tarbiyyah, Baghdad-Beirut: 1984 AD.

36- Mills, John Vetermoris: The Lexicon of Painting, translated by the Department of Arabic Language Sciences, Dr. Ahmed Matlob, the Al-Iraqiya Academic Academy, Baghdad, 2008.

37- Hoda Mahmoud Omar: Industrial Design is Art and Science, The Arab Foundation for Studies and Publishing, Amman, 2004.

38- Henry S. Abboudi: The Dictionary of Semitic Civilizations, Gross Press, Tarabulus / Lebanon, 1991 AD.

39- K.C.Aryan: Basis of Decorative Element in Indian Art, New Delhi, India, 1981. plate (24). 40-Eman Mohamed Wagdy EZZAT, FORMAL FORMULATIONS IN BEADS INSPIRED BY AFRICAN AND NUBIAN ART SYMBOLS FOR STUDENTS OF THE FACULTY OF EDUCATION (CHILDREN'S DIVISION), International Journal of Multidisciplinary Studies in Art and Technology, Vol. 1, No. 2, 2018, pp. 47-50.

Received: February 25, 2019

Accepted: April 2, 2019 